\title{
Monitoreo en prensa impresa sobre las elecciones a gobernador en el estado de Veracruz, período 2010-2016
}

\author{
P. Andrade ${ }^{1}$ - F. M. Mendoza²
}

\section{RESUMEN}

En el siguiente texto se presentan algunos de los principales indicadores que se crearon durante el Monitoreo en prensa impresa sobre las elecciones a gobernador en el estado de Veracruz, durante los períodos 2010 y 2016. El Observatorio Veracruzano de Medios realiza sus seguimientos sobre dos temas, electorales y medioambiente; ambos pretenden recopilar información para hacer estudios longitudinales en el tiempo.

\begin{abstract}
The following text presents some of the main indicators that were created during the print media monitoring of the governor elections in the state of Veracruz, during the 2010 and 2016 periods. The Veracruz Media Observatory follows up on two topics, electoral and environmental issues; both intend to collect information to make longitudinal studies in time.
\end{abstract}

Palabras Clave: Monitoreo, Prensa, Elecciones, Gobernador, Veracruz.

Keywords: Monitoring, Press, Elections, Governor, Veracruz.

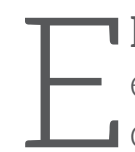

lobjetivo de este monitoreo es abundar en el conocimiento de la opinión pública contemporánea a través del análisis de agenda de medios impresos en Veracruz, comparando sus contenidos durante las campañas electorales 2010y 2016, para gobernador del estado.

Una agenda de noticias está constituida por los temas que tratan los medios y que inciden en la forma en que el público percibe su importancia. Se dice también que las noticias construyen la agenda pública al crear un clima de opinión que determina el posible impulso de la opinión pública.

Los análisis sobre los temas que tratan las noticias no pueden anticipar tendencias polí- ticas, pero si pueden dar a conocer los asuntos que interesan a la política, a los medios y en consecuencia a la ciudadanía, constituyendo así un referente de la comunicación política en campaña electoral.

En la presente nota, se coteja la cobertura que da la prensa por partido en las agendas informativas de los principales diarios de circulación estatal, durante esas campañas electorales.

El análisis de contenido se realizó durante dos semanas naturales y otra aleatoria, de las cuatro en las que transcurre la campaña electoral tanto en el 2010 como en el 2016.

A continuación se muestran los comparativos más relevantes para ambos periodos:

1 Profesora-investigadora en la Universidad Veracruzana. Doctora en Ciencias de la Información por la Universidad Complutense de Madrid. Observatorio Veracruzano de Medios. paandrade@uv.mx

2 Asistente de investigación en el ObVio y en el CEOA-UV. Maestra en Investigación Educativa por la Universidad Veracruzana. Observatorio Veracruzano de Medios. flmendoza@uv.mx 
Notas publicadas en seis periódicos:

Monitoreo Gobernador de Veracruz 2010 y 2016

\begin{tabular}{|c|c|c|}
\hline Diario & Notas publicadas 2010 & Notas publicadas 2016 \\
\hline La Opinión de Poza Rica & 47 & 33 \\
\hline Diario de Xalapa & 94 & 112 \\
\hline Notiver & 223 & 69 \\
\hline El Dictamen & 68 & 63 \\
\hline Mundo de Orizaba & 59 & 38 \\
\hline Diario del Istmo & 104 & 109 \\
\hline Total & 595 & 424 \\
\hline
\end{tabular}

Fuente: Elaboración propia.

\begin{tabular}{|c|c|c|}
\hline \multicolumn{3}{|c|}{ Cobertura de las notas por partido: } \\
\hline \multicolumn{2}{|c|}{ Monitoreo Gobernador de Veracruz 2010 y 2016 } \\
\hline Partido & Notas publicadas 2010 & Notas publicadas 2016 \\
\hline PRI & 297 & 234 \\
\hline PAN & 216 & 146 \\
\hline Movimiento Ciudadano & 82 & 44 \\
\hline Total & 595 & 424 \\
\hline
\end{tabular}

Fuente: Elaboración propia.

Principales hallazgos del Análisis de Contenido:

- En el año 2016 se editaron menos noticias sobre la campaña electoral.

- El Notiver que se edita en el Puerto de Veracruz, y que fue víctima del asesinato de cuatro de sus periodistas, dejó de emitir noticias sobre la campaña electoral en un 70\%.

-En cuanto a la cobertura por partido, son los mismos resultados proporcionalmente, tomando en cuenta que se emitieron menos noticias con referente electoral en la campaña del año 2016.
- Excepto el tema "Corrupción" que obtiene un porcentaje más alto en 2016 tanto por el PAN como por el PRI, los demás temas tienen similar comportamiento en la prensa analizada en ambos periodos.

- Sorprende que el tema "Narcotráfico" no es mencionado como tal en ninguno de los periodos analizado.

- Los temas sobre "Servicios públicos e infraestructura" son los más mencionados por todos los partidos en ambas campañas. 
Notas publicadas en seis periódicos:

Monitoreo Gobernador de Veracruz 2010 y 2016

\begin{tabular}{|c|c|c|c|c|c|}
\hline TEMAS & AÑO & PRI & PAN & $\begin{array}{l}\text { Movimiento } \\
\text { Ciudadano }\end{array}$ & Total \\
\hline \multirow{2}{*}{ Desempleo } & 2010 & $11.69 \%$ & $6.66 \%$ & 0 & $18.35 \%$ \\
\hline & 2016 & $4.46 \%$ & $1.96 \%$ & $0.39 \%$ & $6.81 \%$ \\
\hline \multirow{2}{*}{ Corrupción } & 2010 & $0.55 \%$ & $6.11 \%$ & $2.78 \%$ & $9.44 \%$ \\
\hline & 2016 & $15.74 \%$ & $12.99 \%$ & $3.14 \%$ & $31.87 \%$ \\
\hline \multirow{2}{*}{ Inseguridad } & 2010 & $3.33 \%$ & $10.55 \%$ & $2.78 \%$ & $16.66 \%$ \\
\hline & 2016 & $6.29 \%$ & $3.14 \%$ & $0.39 \%$ & $9.82 \%$ \\
\hline \multirow{2}{*}{ Pobreza } & 2010 & $1.67 \%$ & $1.66 \%$ & 0 & $3.36 \%$ \\
\hline & 2016 & $2.75 \%$ & $0.78 \%$ & $1.57 \%$ & $5.10 \%$ \\
\hline \multirow{2}{*}{ Narcotráfico } & 2010 & 0 & 0 & 0 & 0 \\
\hline & 2016 & 0 & 0 & 0 & 0 \\
\hline \multirow{2}{*}{ Migración } & 2010 & $0.55 \%$ & 0 & 0 & $0.55 \%$ \\
\hline & 2016 & 0 & 0 & 0 & 0 \\
\hline \multirow{2}{*}{$\begin{array}{c}\text { Servicios } \\
\text { públicos e } \\
\text { infraestructura }\end{array}$} & 2010 & $18.33 \%$ & $1.66 \%$ & $2.78 \%$ & $22.77 \%$ \\
\hline & 2016 & $12.59 \%$ & $3.14 \%$ & $2.36 \%$ & $18.09 \%$ \\
\hline \multirow{2}{*}{ Educación } & 2010 & $1.11 \%$ & $2.77 \%$ & 0 & $3.88 \%$ \\
\hline & 2016 & $0.78 \%$ & $1.18 \%$ & 0 & $1.96 \%$ \\
\hline \multirow{2}{*}{ Economía } & 2010 & $15 \%$ & $3.88 \%$ & $2.78 \%$ & $21.66 \%$ \\
\hline & 2016 & $10.23 \%$ & $5.90 \%$ & $0.39 \%$ & $16.52 \%$ \\
\hline \multirow{2}{*}{ Género } & 2010 & $2.22 \%$ & $1.11 \%$ & 0 & $3.33 \%$ \\
\hline & 2016 & $7.08 \%$ & $1.57 \%$ & $1.18 \%$ & $9.83 \%$ \\
\hline \multirow{2}{*}{ Total } & 2010 & $54.44 \%$ & $34.44 \%$ & $11.12 \%$ & $100 \%$ \\
\hline & 2016 & $59.92 \%$ & $30.66 \%$ & $9.42 \%$ & $100 \%$ \\
\hline
\end{tabular}

Fuente: Elaboración propia. 